\title{
Interpretation of diagnosis problem of system level self-diagnosis
}

\author{
Mashkov V.A. ${ }^{1}$, Mashkov O. A. ${ }^{2}$ \\ ${ }^{1}$ University J. E. Purkyne \\ Ceske mladeze 8, Usti nad Labem 40096, Czech Republic \\ ${ }^{2}$ State Ecologikal Academy of Postgraduate Education and management, \\ Ministry of Ecology and Natural Resources of Ukraine \\ 35, Metropolitan Vasil Lypkivskyi str., Kyiv, 03035, Ukraine
}

(Received 1 April 2015)

\begin{abstract}
The paper represents the analysis of the main issues of system level self-diagnosis and explanation of its three basic problems. The main attention is paid to the problem of diagnosis which is expressed with the help of set theory. The influence of made assumptions concerning the allowable faulty sets on the diagnosis results is discussed with the help of simple example.
\end{abstract}

Keywords: diagnosis problem, system, self-diagnosis, set theory, faulty set

2000 MSC: $62 \mathrm{~J} 20,93 \mathrm{~B} 30,03 \mathrm{E} 75$

UDC: 681.518 .54

\section{Introduction}

System level self-diagnosis (SLSD) was introduced by Preparata at al. [1] and has been deeply investigated in literature. It aims at diagnosing systems composed by units (optionally named processing elements), with the requirement that they are able to test each other by exchanging information through available links.

At this level of diagnosis, each particular test is considered as atomic. It means that the details of a test are abstracted (not considered), and only the result of test is taken into consideration. Each test result is expressed via binary variable. It can take values either 0 or 1 . The set of test results is called a syndrome. A syndrome contains information about the states of the system units in coded form. One of the tasks of SLSD is to decode a syndrome by using a diagnosis algorithm.

There are four main issues, which form the context of SLSD.

The first issue is the system testing assignment that defines the possible set of tests among the system units. System testing assignment is relied (defined) and depended on physical connections among the system units.

The second issue is the assumptions underlying the diagnosis algorithms. These assumptions concern the possible faults and the test results, and directly impact the quality of diagnosis (i.e., correctness and completeness).

Correctness means that the detected faulty units are indeed faulty units.

Completeness means that every faulty unit is identified.

The third issue is the organisation of tests performance. It concerns the tasks of test ordering, test repetition, test performing (random or deterministic), etc.

The fourth issue relates to the problem of determining the unit(s), which will perform a diagnosis algorithm and/or will provide environment with the information about system state.

These issues are tightly bounded. Usually the first and second issues are considered together, and they can be viewed as theoretical ground of SLSD. The third and fourth issues are considered together as well, and they are related to the problem of organization of SLSD. 


\section{Basic problems in the theory of system level self-diagnosis}

There have been formulated three basic problems in the theory of SLSD [2,3]. These are:

1. Characterization problem.

To find necessary and sufficient conditions for a system testing assignment which should be satisfied to achieve a given level of diagnosability given a fault model and an allowable family of fault sets.

2. Diagnosability problem.

To determine the family of fault sets that a given testing assignment can diagnose for some fault model. (In other words, to calculate t-diagnosability for the system with given testing assignment).

3. Diagnosis problem.

To determine a fault set from an allowable family, for a given testing assignment, fault model, and syndrome.

The problem of testing assignment (i.e., characterization problem) was the first task, which was considered in context of SLSD. The work of Preparata at al. [1] studied the requirements to the system testing assignment. In this paper, the authors have introduced the diagnosability measure, which to a great extent depends on the system testing assignment. A diagnosability measure reflexes the capability and quality of diagnosis of the system given particular testing assignment.

Particularly, in this paper, there was proved that for correct diagnosis of at most $t$ faulty units there must be satisfied the following two requirements:

- a system must have $\mathrm{n}$ units, where $n \geqslant 2 t+1$;

- each system unit must be tested by at least $t$ distinct other units.

Convenient form for presenting the testing assignment is graph model. General presentation of such graph model is as follows.

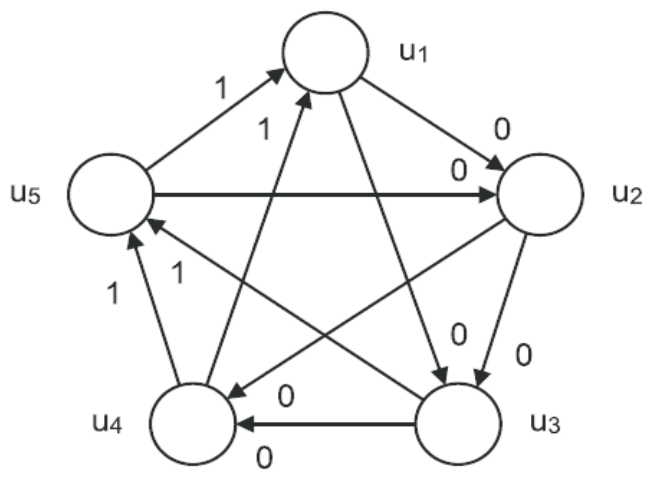

Fig. 1. Example of testing graph.

A diagnosable system $S$ consists of $\mathrm{n}$ units denoted by the set $U=\left\{u_{1}, u_{2}, \ldots, u_{n}\right\}$, where each unit $u_{i} \in U$ is assigned a particular subset of the units in $U$ to test. Generally, each unit can test itself, but in most researches it is assumed that units don't do this. A test link, denoted by $\tau_{i j}$, means that the unit $u_{i}$ tests the unit $u_{j}$. The complete collection of tests in $S$ is called the testing assignment of $S$. Testing assignment of $S$ can be represented by a directed graph $G=(V, E)$, called the testing graph. Each vertex $v_{i} \in V$ of $G$ represents a unit $u_{i}$ and edge $e_{i j} \in E$ represents the test which is performed by unit $u_{i}$ on unit $u_{j}$. Test result is represented by binary variable $r_{i j}$, such that $r_{i j}=1$ if unit $u_{j}$ has not passed the test, and $r_{i j}=0$ otherwise.

In Fig. 1, the example of testing graph is shown. A label on an edge is the result of that test. 


\section{Diagnosis problem}

The set of test results is known as a syndrome. The identification of the set of faulty units on the basis of a given syndrome is called diagnosis. The problem of diagnosis can be expressed with the help of set theory. In the given case, there are two sets: $S_{F}$ and $S_{R}$ (see Fig. 2). $S_{F}$ is the set of possible faulty situations (fault sets); $S_{R}$ is the set of possible syndromes.

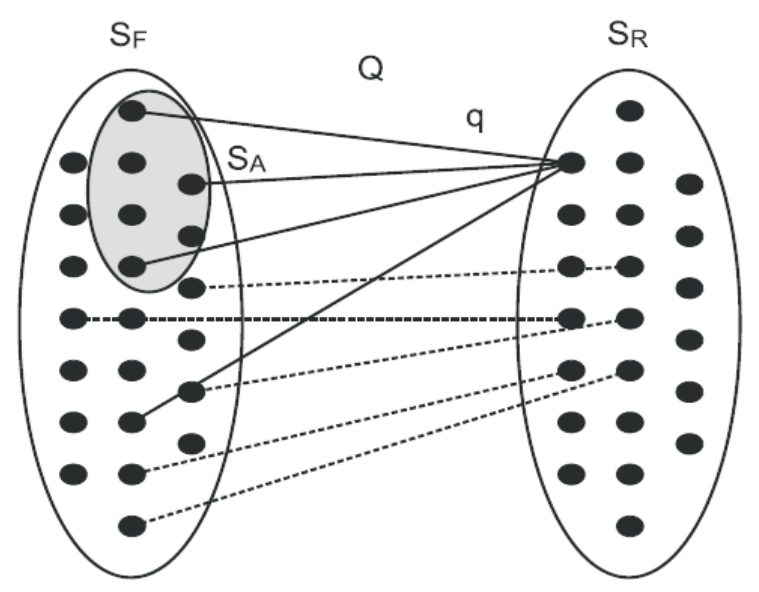

Fig. 2. Binary relation $Q$ from a set $S_{F}$ to a set $S_{R}$.

There is binary relation $Q$ from a set $S_{F}$ to a set $S_{R}$. When a syndrome $R, R \in S_{R}$ is obtained, only part of $Q$ is essential, particularly $q$ (see Fig. 2). The task of diagnosis is to determine $\operatorname{dom}(q)$. Generally $\operatorname{dom}(q)$ includes many members (elements) of $S_{F}$. Structure of any $R$ is entirely defined by the system testing assignment.

Assumptions that could be made about the allowable faulty sets can reduce considerably the set $\operatorname{dom}(q)$ to the set $S_{A}$. It means that if the made assumptions are satisfied then only faulty sets, which are in $S_{A}$ are subject for diagnosis. The case when $S_{A}$ includes only one faulty set $F$ is considered as unique diagnosis. If the set $\mathrm{SA}$ includes more than one faulty set $\left(F_{1}, F_{2}, \ldots, F_{m}\right)$ then there are possible several diagnosis strategies. Firstly, it is possible to find

$$
\bigcap_{i=1}^{n} F_{i} .
$$

In this case, the diagnosis is correct but may be incomplete. Such diagnosis is known as sequential diagnosis [4].

Secondly, it is possible to find

$$
\bigcup_{i=1}^{n} F_{i} .
$$

This strategy yields complete but possibly incorrect diagnosis. Such diagnosis is known as excess diagnosis [5].

Thirdly, it is possible to estimate the probability of occurrence of each fault set and chose the most probable one. Diagnosis performed according to this strategy is known as probabilistic diagnosis [6].

From the above, it is evidently the role of made assumptions and its impact on correctness and completeness of diagnosis.

Generally, the assumptions can be made in relation to the faulty model of a unit and to the test results that a unit can produce. Faulty model of a unit can contain one of the two possible types of faults. Unit can be either a permanently faulty or an intermittently faulty. In relation to the 
Table 1. Test results and their probabilities.

\begin{tabular}{|l|c|c|c|}
\hline \multirow{2}{*}{ Test result and its probability } & \multicolumn{2}{|c|}{ Testing unit $u_{i}$} \\
\cline { 3 - 4 } Tested unit $u_{j}$ & fault-free & faulty \\
\hline \multirow{3}{*}{ fault-free } & $r_{i j}=0\left(P_{C}\right)$ & $r_{i j}=0\left(1-P_{S}\right)$ \\
\cline { 3 - 4 } & \multirow{2}{*}{ faulty } & $r_{i j}=1\left(1-P_{C}\right)$ & $r_{i j}=1\left(P_{S}\right)$ \\
\cline { 3 - 4 } & $r_{i j}=0\left(1-P_{A T}\right)$ & $r_{i j}=0\left(1-P_{F}\right)$ \\
\cline { 3 - 4 } & $r_{i j}=1\left(P_{A T}\right)$ & $r_{i j}=1\left(P_{F}\right)$ \\
\hline
\end{tabular}

whole system there possible the situation when some of system units may be permanently faulty and some units may be intermittently faulty. Such faulty situation is known as hybrid faulty situation. Assumption made in relation to the test results can be expressed with the probabilities that describe the possible values of $r_{i j}$ given different states of testing units $u_{i}$ and tested unit $u_{j}$ (see Table 1 ).

Table 1 presents the general approach when all results are possible with defined probabilities. This approach was introduced by Blount [7]. Probabilities presented in the table mean the following: $P_{C}$ is the probability that fault-free unit will identify correctly the tested fault-free unit. It means that connection between units can fail. $P_{A T}$ is the probability that fault-free unit will identify correctly the tested faulty unit; $P_{S}$ is the probability that faulty unit produce the test result equal to 1 when tested unit is fault-free; $P_{F}$ is the probability that faulty unit produces the test result equal to 1 when the tested unit is faulty.

For each particular research the probabilities presented in Table 1 are specified by way of introducing certain assumptions. The first framework in the system-level diagnosis area was proposed by Preparata, Metze, and Chien (so called PMC model) [1]. PMC model deals with the following assumptions:

- only permanent fault of unit is allowed;

- a fault-free unit always detects the fault in the tested unit (i.e., has $100 \%$ fault coverage);

- the result of the test performed by a faulty unit is unpredictable not depending on the states of tested units.

When the assumptions of PMC model are taken in consideration the following reductions in Table 1 are possible: $P_{C}=1$ and $P_{A T}=1$. PMC model is related to the symmetric invalidation model. In such model, a testing faulty unit can produce test result either 1 or 0 , irrespective of the state of the tested unit. The asymmetric invalidation [8] differs from the symmetric invalidation only in the case when both the testing and tested units are faulty. In this case, a testing faulty unit produces test result always equal to 1 .

\section{Diagnosis of system consisting of three units}

Let's consider simple example to elucidate the assumptions that could be made. Consider a system consisting of three units. Units have performed tests with the results depicted in Fig. 3.

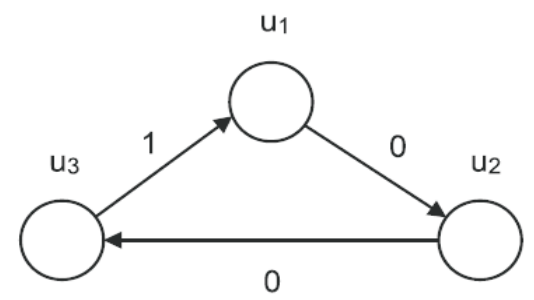

Fig. 3. Simple example with three units. 
For simplicity reason let's assumed that only permanent faults are allowed. This assumption reduces considerably the total number of possible faulty sets. Now, only 8 faulty sets should be considered. For this case, two sets, $S_{F}$ and $S_{R}$, will be as follows (see Fig. 4 ).

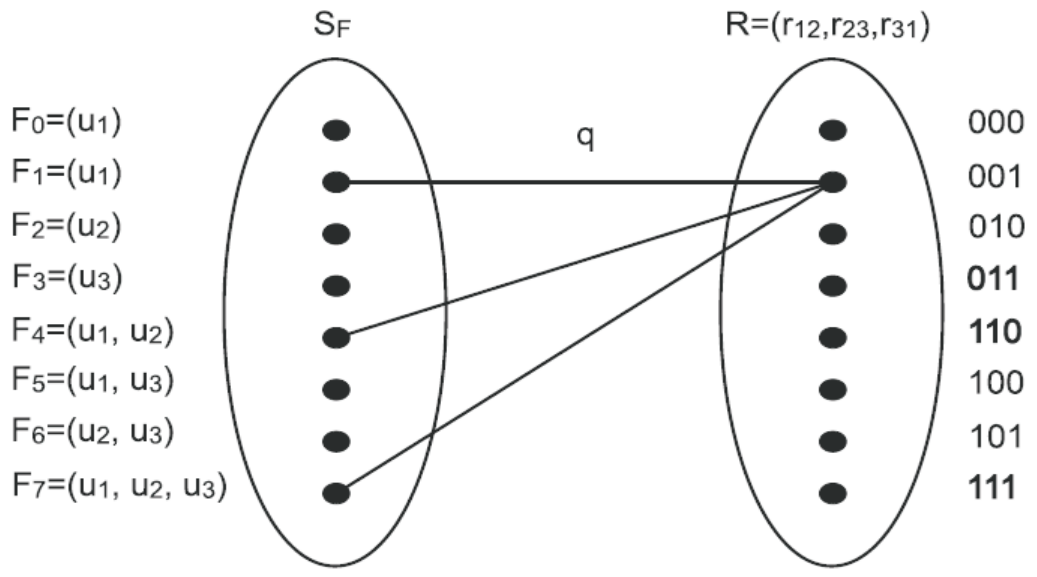

Fig. 4. Relation between faulty sets $S_{F}$ and syndromes $R$.

It is easy to conclude that only faulty sets $F_{1}, F_{4}$ and $F_{7}$ can produce the syndrome $R=\{0,0,1\}$. In order to diagnosis will be unique it is needed to set and consider additional parameters. One of such parameters can be set based on the set $S_{R}$, respectively based on the structure of testing assignment. For each structure of testing assignment there can be computed the parameter, which reflexes the maximal number of faulty units a system can guarantee to detect correctly. This parameter is usually called the degree of diagnosability or diagnosability measure, $t$.

The structure of testing assignment depicted in Fig. 3 has $t=1$. It means that when not more than one faulty unit can occur in system the diagnosis is unique. Thus, decoding the syndrome $R=\{0,0,1\}$ gives the result: unit $u_{1}$ is faulty and units $u_{2}$ and $u_{3}$ are fault-free.

There have been developed many algorithms allowing to identify a fault set uniquely (when some assumptions are made about the faulty units). The main task while developing these algorithms is to reduce their complexity. Among the most efficient algorithms there could be named algorithm proposed by Dahbura and Masson [9] which has $\mathrm{O}\left(N^{2.5}\right)$ time complexity and $\mathrm{O}\left(t^{3}+|E|\right)$ algorithm suggested by Sullivan [10]. Both algorithms were developed for $t$-diagnosable systems under the symmetric invalidation model and when permanent fault are allowable only. There are many special classes of $t$-diagnosable systems that support more efficient diagnosis techniques than above mentioned ones, and this is reason to believe that an $\mathrm{O}(|E|)$ diagnosis solution exists for all $t$-diagnosable systems. Preparata et al. defined the $D_{\delta t}$ structure in which unit $u_{i}$ tests $u_{j}$ if and only if

$$
j-i=\delta m(\bmod n),
$$

where $m=1,2, \ldots, t$.

Meyer and Masson [11] gave $\mathrm{O}(n t)$ solution to the case of $\delta=1$.

The efforts to develop the simplest algorithm are continue till now.

\section{Conclusions}

Diagnosis problem of system level self-diagnosis can be expressed with the help of set theory and can be depicted via binary relation from a set of possible faulty situations to a set of possible syndromes. Such graphical representation of system diagnosis allows to elucidate the possible diagnosis strategies 
and allows to assess the impact of made assumptions in relation to the test results on the quality of diagnosis.

Presented in the paper analysis of diagnosis problem should help the researchers to choose the appropriate diagnosis strategies for diagnosis of particular complex systems.

[1] Preparata T., Metze G., Chien R. On the connection assignment problem of diagnosable system. IEEE Transactions on Electronic Computers. EC-16, n.12, 848-854 (1967).

[2] Barborak M., Malek M., Dahbura A. The consensus problem in fault-tolerant computing. ACM Computing Surveys. 25, n.2, 171-220 (1993).

[3] Somani A. K. System Level Diagnosis: A Review. (1997) [online]. Available from http://citeseerx.ist.psu.edu/viewdoc/summary?doi=10.1.1.52.9488.

[4] Chang Y. M., Yeh J. M. A new sequential diagnosis algorithm in hypercubes with high diagnosability. In International Computer Symposium, Taiwan (2004).

[5] Somani A. K., Agarwal V. K., Avis D. A generalized theory for system level diagnosis. IEEE Trans. Comput. C-36, 538-546 (1987).

[6] Fujiwara H., Kinoshita K. Some existence theorems for probabilistically diagnosable systems. IEEE Trans. on Comp. C-27, n.4, 297-303 (1981).

[7] Blount M. L. Probabilistic treatment of diagnosis in digital systems. In 7th IEEE Int. Symp. On FaultTolerant Computing. 72-77 (1977).

[8] Barsi T., Grandoni T., Maestrini P. A theory of diagnosability of digital systems. In IEEE Trans. on Comput. C-25, n.6, 585-593 (1976).

[9] Dahbura A., Masson G. An $\mathrm{O}\left(N^{2.5}\right)$ fault identification algorithm for diagnosable systems. IEEE Trans. Comput. C-33, 486-492 (1984).

[10] Sullivan G. An $\mathrm{O}\left(t^{3}+|E|\right)$ fault identification algorithm for diagnosable systems. IEEE Trans. Comput. C-37, 388-397 (1988).

[11] Meyer G., Masson G. An efficient fault diagnosis algorithm for symmetric multiple processor architectures. IEEE Trans. Comput. C-27, 1059-1063 (1978).

\title{
Інтерпретація задач самодіагностики на системному рівні
}

\author{
Машков В. А. ${ }^{1}$, Машков О. А. ${ }^{2}$ \\ ${ }^{1}$ Чеський національний університет м. Устье над Лабем \\ вул. Чеська молодь, 8, м. Устье над Лабем, 40096, Чехія \\ ${ }^{2}$ Держсавна екологічна академія післядипломної освіти та управління Мінприроди України \\ вул. Митрополита Василя Липківського, 35, Київ, 03035, Україна
}

Подано аналіз головних задач самодіагностики на системному рівні. Наведено по-

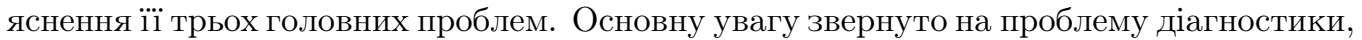
яка розв'язується за допомогою теорії множин. На конкретному прикладі розглянуто вплив зроблених припущень відносно можливих відмов на результати діагностики.

Ключові слова: задача діагностики, система, самодіагностика, теорія множин, набір відмов

2000 MSC: 62J20, 93B30, 03E75

УдК: 681.518 .54

Mathematical Modeling and Computing, Vol. 2, No.1, pp.71-76 (2015) 